\title{
Clinical Issues in Tele-Analysis: Cyber-Intimacy
}

\author{
Chang-Hun Lee \\ Lee Chang Hun Psychiatric Clinic, Ulsan, Korea
}

\section{원격 정신분석적 치료에서의 임상적 문제: 가상현실에서의 친밀함}

\author{
이 창 훈 \\ 이창훈 정신건강의학과의원
}

Hyper-connectivity and despatialization that represent current society ask us to accept and apply tele-analysis to the field of psychoanalytic psychotherapy and psychoanalysis. Psychoanalysis has preserved values of ambiguity, discomfort and time consuming tasks which, even though modern people devalue their values, is necessary to have empathy, internalize representations of each other, and establish internal intimacy. Tele-analysis, however, has contrary aspects to values which psychoanalysis has preserved. It is why many researchers have continued to the debate about advantages and disadvantages of tele-analysis. I will discuss the possibility of clinical use and predicted clinical problems of tele-analysis through reviewing recent studies and literature and my clinical experiences about tele-analysis. I like to empower therapists to overcome prejudice about the usefulness of tele-analysis, and clearly recognize its clinical problems. It will lead us to prepare for the era of Internet which must apply to psychoanalytic psychotherapy and psychoanalysis and make the value and the possibility of psychoanalysis more widely understood and accepted.

Psychoanalysis 2019;30(3):42-49

KEY WORDS: Tele-analysis · Despatialization · Cyber-intimacy.

Received: March 25, 2019 Revised: April 14, 2019 Accepted: April 22, 2019

Address for correspondence: Chang-Hun Lee, MD

Lee Chang Hun Psychiatric Clinic, \#401 Kolon Park Police shopping arcade, 241 Daegongwon-ro, Nam-gu, Ulsan 44667, Korea

Tel: +82-52-265-2051, Fax: +82-52-265-2071, E-mail: baltro@hanmail.net

\section{서 론}

21세기 사회 현상을 대표하는 '4차 산업혁명'은 정보 · 통 신기술의 융합으로 이루어지는 차세대 산업혁명을 의미하 며, 초연결(hyperconnectivity)과 초지능(superintelligence) 을 특징으로 한다(pmg, 2016). 이러한 시대적 흐름은 필연적 으로 정신치료 분야에도 새로운 흐름을 낳았다. 통신기술과 소셜미디어가 정신치료에 접합될 수 있는 가능성을 찾으려 는 연구자들은 전화나 인터넷 기반의 통신을 정신치료의 매 개체로 사용하는 것부터, 인공지능 기계가 정신치료자의 역할 을 대신하는 가능성까지 고려하고 있다(Turkle 2017; Scharff 2012b).

최근 수십 년간 정신분석적 치료에서 전화나 스카이프의 도움으로 공간의 제약을 뛰어넘어, 도시와 도시, 대륙과 대

This is an Open Access article distributed under the terms of the Creative Commons Attribution Non-Commercial License (https://creativecommons.org/licenses/by-nc/4.0) which permits unrestricted non-commercial use, distribution, and reproduction in any medium, provided the original work is properly cited.
양을 사이에 두고도 정신치료를 가능하게 하는 시도에 많은 정신치료자들이 뛰어들었다. 초기의 회의적이고 우려 섞인 시각은 현실적인 이유와 즉각적인 성과들에 밀려났다. 그러 나 달궈진 돌이 채 식기 전에 최근 여러 정신치료자들이 애 초의 부정적인 목소리에 다시 귀를 기울이고 있다. 원격 정 신분석적 치료의 선봉에 섰던 정신치료자들 중 몇몇은 그동 안 쌓은 자신의 임상경험을 통해 원격 정신분석적 치료의 함정을 생생하게 전해준다.

정신분석은 '같은 방에 함께 있는 것'의 중요성을 지켜왔 다(Turkle 2017). 그동안 정신분석 분야의 치료자들이 원격 정신분석적 치료에 대해 보수적 태도를 취해온 것도 이 때 문이다. 그래서인지 정신분석가들은 자신들의 임상경험에 서 얻은 결과를 공공연히 발표하는 것이 조심스러운 것 같 다. 세간에는 원격 정신분석적 치료에 대한 연구와 임상경험 을 바탕으로 한 상당한 수의 문헌들이 발표되고 있지만, 주요 정신분석 연구논문을 온라인으로 열람하는 Psychoanalytic

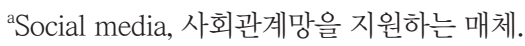


Electronic Publishing에는 전화, 스카이프를 이용한 원격 정 신분석적 치료에 대한 연구발표가 2017년까지 16편이 전부 이다. 그러나 2001년, 미국심리학회의 120 명의 치료자에게 조사한 결과 최근 2년간 원격 분석적 정신치료를 한 적이 있 었던 치료자는 83\%였고, 앞으로 치료를 유지할 수 있는 방법 이 원격치료밖에 없을 경우에 원격 정신분석적 치료를 할 의향이 있는 치료자는 86\%였다(Richards 2001). 20년이 지 난 현재에는 컴퓨터와 인터넷 보급률이 높은 지역이라면 원 격 정신분석적 치료를 전혀 하지 않은 분석가는 매우 드물 것이다. 최근 20년간 국제정신분석학회의 주요 공식회의에 서 원격 정신분석적 치료에 대한 연구발표와 패널 토의는 단 한 번도 제외된 적이 없었다(www.ipa.world). 이제 원격 정신 분석적 치료는 자의이든 타의이든 정신분석적 치료 임상에서 제외할 수가 없는 부분이 되었다.

저자는 원격 정신분석적 치료에 관한 논의의 핵심은 치료 공간의 탈공간화 ${ }^{\mathrm{b}}$ (despatialization)가 환자의 심리적 현실 (psychic reality)과 치료과정에 미치는 영향과 그 역동적 의 미에 있다고 생각한다. 치료공간의 탈공간화란 환자와 치료 자가 분석실이라는 물리적 공간을 벗어나 치료가 이루어지 는 상태를 의미한다. 분석 세팅의 탈공간화라는 조류 속에 물리적 요소(분석가와 환자의 몸, 분석실)가 갖는 임상적 의 미가 재조명되고 있다.

이 논문에서 저자는 먼저 탈공간화가 자기(self)와 관계(relationship)에 미치는 영향을 알아볼 것이다. 그 후에 통신기술 을 이용한 원격 정신분석적 치료에서의 임상적 문제를 살펴 볼 것이다. 최근의 문헌들을 고찰하여 현재 당면한 임상 문 제에 대한 논의를 촉구하고 유익한 의견 수렴을 위한 발판 을 마련하고자 한다.

\section{자기(Self)와 친밀함(Intimacy)의 재조명: 탈공간화가 미치는 영향}

4차 산업혁명이 가져다 준 초연결성은 시간과 공간 차원 에 대한 우리의 인식에 변화를 일으켰다(Stadter 2013). 시간

${ }^{\mathrm{b}}$ 저자는 원격 정신분석적 치료에서 치료공간이 치료자의 방에서 벗 어나 물리적 공간의 제약을 받지 않게 되는 현상을 치료공간의 '탈 공간화'로 이름 붙였다. 원격 정신분석적 치료의 경우에도 가상의 분석공간이 가지는 심리적/상징적인 의미는 환자와 치료자의 내면 에 부분적으로 지속될 것이다. 그러나 물리적인 치료공간, 즉 환자 와 치료자가 같은 방에 실제로 함께 있는 물리적 공간이 사라짐으로 써 치료공간의 심리적, 상징적 의미는 환자와 치료자 모두에서 변화 될 수밖에 없다고 생각한다. 여기에서 치료공간은 물리적인 공간의 의미로 사용했고, 분석공간은 분석적 치료가 이루어지는 심리적/상 징적 의미를 가지는 가상의 공간이라는 의미로 사용되었다.
과 공간은 인간이 가진 물리적 한계의 핵심이다. 우리는 외 부현실에서 시간과 공간의 제약에 적응하고, 내적 세계에서 는 시공의 제약을 왜곡하는 판타지를 만든다. 외부현실의 제 약과 내적 판타지의 간극에 머무르면서 끊임없이 조율하여 균형을 이루도록 애쓰는 과정은 정신분석적 치료과정 자체 이다. 욕망과 한계의 간극에서 좌절하고 자기 자신을 헤아리 는 과정에서 우리는 타인을 헤아리고 타인을 원하게 된다. 바 로 친밀한 관계를 자기 자신 안으로 받아들이게 된다. 그러나 현재는 눈부시게 발전한 통신기술의 덕으로 우리의 내적 판 타지와 현실의 구분이 모호할 정도로 그 간극이 허물어졌다. 불과 20년 전만 해도 상상에서나 가능했던 일들이 현실이 되 었다. 어디서든 인터넷에 접속해 지구 반대편에 있는 사람과 얼굴을 보며 이야기할 수 있다. 세계 각 도시에 흩어져 있는 사람들이 한꺼번에 한 사이버 공간에서 만나 토론을 할 수 있 다. 이제는 시간과 공간의 제약 아래에 있던 인간관계의 여러 측면들이 제약에서 풀려나 봇물 터지듯 넘쳐흐르고 있다.

몇몇 연구들은 인터넷과 소셜미디어가 사회 관계망을 확 장하고 관계에 드는 비용을 획기적으로 줄여, 보다 빠르고 보다 쉽고 보다 저렴하게 관계를 맺게 도와준다는 면에서 긍 정적인 효과를 찾았다(Boase 등 2006). 인터넷을 통한 사회 적 모임(밴드, 인터넷동호회, 소셜데이팅)이 인간관계의 매 개체로 역할을 하거나, 사회불안이나 관계불안이 심한 경우 에 소셜미디어를 이용하여 소통을 시작하는 것으로 관계의 문턱을 낮추는 효과도 있다.

그러나 어떤 연구들은 인터넷과 소셜미디어의 부정적인 영향에 주목하고 있다(Nie와 Erbring 2002). 관계의 매개체 로서 사용되는 것에서 그치지 않고 가상관계가 실제 관계를 대체하여 대인관계의 단절을 가져왔다. 우리가 인터넷으로 세상과 연결하고 있는 동안, 실제 세상에서만 얻을 수 있는 것을 놓치고 있는 것은 아닌지 스스로에게 되물어야 할 것 이다. 스크린을 통한 의사소통이 실제 의사소통에서 가능한 것을 모두 다 제공하지 않는다는 것은 명백하다. 서로 안고 어루만지고 손을 잡아주는 것, 화면이나 통화음에서는 간파 하기 어려운 몸 어딘가의 변화, 미묘한 분위기, 체취 등은 인 터넷 소통에서 전달되지 않는다. 오히려 인터넷에서는 전달 될 수 없는 것이 있기 때문에, 불편과 갈등을 피할 수 있는 수 단으로 사용되는 경우도 많다. Turkle(2017)은 시리아 난민 의 삶을 가상현실로 체험하는 프로그램에 대해 언급하면서 '직접 갈 수 없어서' 인터넷을 이용한다는 이유는 그 이면에 '가기 싫어서'라는 이유를 숨기고 있다고 봤다. 우리는 컴퓨 터 앞에 앉아서 불편한 것들은 바로 차단하고 바꿔버릴 수 있다. 분노, 수치심, 열등감, 적개심과 같은 불편한 감정을 외부로 투사하는 수고조차도 할 필요 없이 익명으로 바로 
배출할 수 있고, 인터넷에서 로그아웃 함으로써 자신의 감정 배출이 낳는 결과를 모르고 지낼 수 있다. 이별 통보를 이메 일을 통해 하거나, 집 안에서도 각방에서 문자메시지(예로 카카오톡)로 자녀에게 훈계를 하고 아이도 문자 메시지로 부 모님께 반항하면서, 얼굴 보고서는 전하지 못할 마음을 쉽게 배출하는 경우도 있다. 보다 쉽고 편리하게 인간관계를 연결 하는 수단이 인간관계의 단절을 낳을 수도 있다는 역설을 인 식할 필요가 있다.

Akhtar(2010)는 인터넷 환경이 외부현실에 더 쉽게 접촉 하고, 내면의 표현에 더 자유로워지며, 의사소통을 촉진하는 긍정적인 영향도 있지만, 습관적으로 자기를 노출하고, 실제 관계는 축소되고, 공감능력이 감소하는 부정적인 영향이 있 다고 지적했다. Konrath 등(2011)은 최근 30년 동안 대학생 들의 공감능력이 $40 \%$ 감소했고, 이것이 모바일 인터넷, 통 신기기를 사용하는 것과 깊이 연관되었을 것으로 생각했다. 또 인터넷을 검색하는 동안 뇌 활동이 저하되는 것을 관찰한 연구도 있는데, $\operatorname{Carr}(2010)$ 는 최근 연구를 리뷰하여 인터넷 을 사용하는 동안 우리는 겉핝기식의 읽기, 조급하고 산만한 사고방식, 얕게 학습하는 환경에 익숙해지게 된다는 결론을 내렸다(Stadter 2013).

이제 인터넷 문화가 자기(self)와 관계(relationship)에 미 치는 부정적인 영향에 보다 초점을 두어 살피고자 한다. 한 곳에 함께 있는 것이 관계의 필수 조건인 시대가 있었지만, 이제 관계는 물리적 공간의 제약을 받지 않게 되었다. 이를 '관계의 탈공간화(despatialization)'라고 할 수 있다. 한곳에 함께 있지 않아도 관계를 맺을 수 있다는 것이 관계의 탈공 간화의 핵심이라고 생각한다. 인간관계가 공간의 제약을 거 의 받지 않게 되면서, 역설적으로 관계는 인간 내면에 내재 화(internalization)되기 힘들어졌다. 한곳에 함께 있는 것은 서로의 내적 표상을 내재화하고 내적 친밀함을 성장시키는 데 필수적인 요소이다. 내적 친밀함은 상대가 한곳에 함께 있지 못할 때도 함께 있는 것과 같이 친밀하다는 신뢰를 통 해 굳건해지는데, 이를 위해서는 함께하는 때와 함께할 수 없을 때를 번갈아 반복하면서, 대상과의 상호작용이 수없이 반복되어야 한다. 이렇게 하여 서서히 자신과 대상에 대한 통합된 내적 표상이 확고하게 형성되고, 그런 후에 서로가 함께 있지 못할 때에도 상대를 자신의 내면에 품고 내적 관 계를 지속할 수 있다.

그러나 지금은 떨어져 있어도 소리나 문자(텍스트 메시지) 혹은 영상으로 실시간 함께할 수 있으므로 상대를 자신의 내 면에 내재화하기 위해 애쓸 필요가 없게 되었고, 물리적 감 각으로 확인할 수 있는 것 이외는 신뢰하기 어려운 지경에 이르게 되었다. 왜냐하면 한 공간에 있지 않아도 함께 있는
것처럼 느끼게 하지만, 오히려 감각으로 확인될 수 없는 것은 (전자기기를 통해 전달되는 소리와 이미지, 영상으로 확인할 수 있는 것) 존재하지 않는 것처럼 느끼게 되기 때문이다. 통 신기기와 인터넷을 통한 관계에서는 자기(self)와 대상 $\left(\mathrm{ob}^{-}\right.$ ject)을 부분 대상(part object)으로 인식하게 될 수 있으며 편 하고 좋은 것과 불편한 것들은 분리(splitting)시키는 방어기 제가 강화될 수 있다.

Stadter(2013)는 통신기술과 소셜미디어가 인간의 자기 (self)와 관계(relationship)에 어떤 영향을 미치는지를 연구 했는데, 초연결적 통신과 소셜미디어를 서비스하는 전자기 기가 치료관계 속에 들어올 때 $\mathrm{e}$-third'로서 존재한다고 하 였다. 그는 현대 인터넷 문화를 자기(self)와 대상(object)의 파편화(fragmentation), 그리고 e-third와의 공존이라고 요 약하였다(Stadter 2013). 그는 e-third의 영향을 다음과 같이 정리하였다. 우리는 e-third를 분절된 자기(fragmented self) 와 분절된 대상(fragmented object)으로 인식하게 된다. $\mathrm{e}^{-}$ third는 이행 대상(transitional object)으로서 작용하여 실제 인간관계나 치료관계를 지속시키고 강화하는 매개체의 역할 을 할 수도 있고, e-third가 자기애적 요소에 영합하여 자기 애적 병리를 부추키는 경우도 있다. e-third를 통해 과장된 자기(grandiose self)로서의 왜곡된 정체성을 만들게 될 경우, 실제의 삶과 실제 관계는 무너질 수 있다.

인터넷 문화는 이제 우리가 거부하거나 부정할 수 있는 것이 아니다. 그러나 인터넷 문화(e-culture)가 속도와 확실 성, 현재와 최신의 것, 멀티태스킹에 가치를 두는 반면, 정신 분석적 치료는 등한시되는 우리 마음의 상태에 대한 관심을 환기시킨다(Stadter 2013). 정신역동에 대한 감수성은 자기 성찰과 인내심, 판단의 유보, 불확실함의 가치를 수호하며, 알지 못하는 상태와 불편한 감정 상태를 견디는 것의 중요성 을 지키고 있다(Stadter 2013). 그러므로 정신분석적 정신치 료의 임상에서 통신기기와 인터넷을 사용하는 것은 이 시대 의 역설이다. 하지만 인터넷 문화가 모두의 삶에 일부, 내 몸 의 피부와 같이 인식되는 세상에서 정신분석적 치료만이 오 염되지 않은 순수 영역으로 남아있겠다고 해서 사람이 다니 지 않는 무인도가 된다면 무슨 의미가 있겠는가? 이제는 대 부분의 정신치료자들이 새로운 현실에 적응하고 사람들의 요구에 발맞추기 위한 방법을 찾는 것에 관심을 기울이고

${ }^{\mathrm{c} T}$ Tomas Odgen이 명명한 분석적 제삼자(analytic third)에 대비하여, Stadter는 치료관계 안에 실물로서 존재하는 전자기기를 e-third라 고 명명하였다. Odgen은 정신분석 세팅 안에서 환자와 분석가의 개별적 주관성이 의식적/무의식적으로 상호 소통하면서 상호주관 적 제3의 공간(intersubjective third space)이 창조된다고 보았고, 이를 분석적 제삼자(analytic third)라고 명명하였다. 
있다(Scharff 2012a; Brahnam 2017). 인터넷 문화를 정신분 석적 치료에 접목하였을 때, 그 긍정, 부정적 영향을 연구함 으로써 정신분석적 치료의 가치와 중요성을 재조명하고 환 기시킬 수 있을 것이다. 그리고 통신기술과 인터넷을 정신분 석적 정신치료에 효과적으로 이용하기 위해 무엇이 필요한 지 연구해야 할 과제가 우리에게 있다.

\section{통신기술을 이용한 원격 정신분석적 치료}

환자가 몇 개월간 다소 먼 도시로 파견근무를 간다고 이 야기한다. 그러면서 다른 도시에서도 통신기기를 이용하여 치료를 이어가기를 원한다고 말한다. 외부현실이 환자의 치 료과정에 어떤 영향을 줄 것인가? 치료에 대한 저항인가? 하 는 생각과 더불어 먼 도시에 있는 동안 치료를 중단할 것인 지, 통신기술을 이용하여 치료를 지속하는 것이 나을지를 고 민해야 한다. 또 다른 경우 치료가 잘 진행되고 있던 환자가 갑자기 해외유학을 결정했다고 이야기한다. 전이치유인가? 진정한 독립과 성취인가? 하는 고민과 더불어 해외에서 원격 으로 (통신기술을 이용한) 치료를 계속할지, 치료종결을 준비 할지에 대한 고민을 해야 한다. 4차 산업혁명이 모든 사람의 삶을 크게 바꾸어 놓았고, 당연한 결과로 치료과정에도 영향 을 미치게 되었다. 환자와 치료자의 생활에는 예시와 같이 먼 거리의 이동이 불가피한 일들이 많이 일어날 수밖에 없게 되었다. 이제는 치료과정 중에 통신기술을 이용하여 원격으 로 치료를 지속할지에 대해 한번쯤 고민하는 것이 대다수의 정신치료에서 일어나고 있다.

\section{원격 정신분석적 치료에 대한 논쟁}

정신분석적 치료에 통신기술을 사용할지 선택하는 데 있 어 발생하는 논쟁점은 통신기술과 사회통신망이 자기와 관 계에 미치는 영향에 대한 이분적인 시각과 맞닿아 있다. 어 떤 분석가들은 원격 정신분석적 치료에서는 분석과정이 제 대로 발달할 수가 없다고 우려한다(Scharff 2012a; Yamin 2003). 치료실이라는 공간은 정신분석적 치료의 틀(frame, setting)에 큰 부분을 차지하고 있고, 치료의 틀 안에서 분석 적 공간(analytic space)이 창조된다. 원격 정신분석적 치료에 서는 치료의 틀이 불분명해지고, 따라서 분석적 공간이 제대 로 발달할 수가 없다는 시각이다.

이와 반대로 어떤 분석가들은 원격 정신분석적 치료에서 는 기존의 정신분석적 치료에서 발달하는 모든 분석과정이 거의 차이가 없이 일어난다고 주장한다(Saul 1951; Leffert 2003; Lindon 2000; Scharff 2012a). 치료자의 방으로부터
벗어나, 환자와 치료자가 인터넷 공간에서 만나는 것으로 이 해하면 분석적 공간이라는 이행적 공간(transitional space) 의 무한한 확장으로 볼 수 있다. 그 분석적 공간에서 환자와 치료자는 모든 형태의 전이와 역전이를 충분히 경험하고 이 해하고 해석할 수 있다는 시각이다. 함께 있지 않고, 보이지 않음으로써 보다 강렬한 감정을 표현할 수 있도록 하고, 치 료자 또한 환자의 위험한 행동으로부터 안전하기 때문에 횔 씬 위험한 환자를 치료하는 데 더 포용적일 수 있다는 주장 도 있다(Mirkin 2011).

분명 피치못할 사정으로 치료가 중단될 위기에 있거나, 너 무 멀어서, 혹은 신체의 제약(거동이 불가능하거나, 심한 병 리로 인해 외출이 불가능한 경우)으로 치료의 기회가 없었던 경우에 원격 정신분석적 치료는 치료실이라는 이행적 공간 (transitional space)을 무한대로 확장되게 만들 수 있는 유용 한 방법이다. 그러나 Turkle(2017)은 없는 것보다는 대체할 것이 있는 것이 낫다고 판단하는 손쉬운 결정에 함정은 없는 지 질문을 던지면서, 정신치료자가 자신의 어쩔 수 없는 한 계로 인해 완전한 공감과 이해에 이르지 못하는 좌절감으로 부터 벗어나고 싶은 욕구 때문에 원격치료의 장점에서 눈을 떼지 못하는 것은 아닌가 하는 문제 제기를 했다. 환자는 '분 석가의 진료실에 갈 수 없으니까'라고 말하지만, '분석가와 함께 있고 싶지 않아서'는 아닌지, 다시 말해 환자와 치료자 의 깊숙하고 거대한 저항이 도처에 숨어있는 대양에서 분석 이라는 함선은 안전한 항해를 할 수 있는 것인지 생각해 보 아야 한다는 것이다.

대부분의 치료자들은 원격 정신분석적 치료를 '없는 것보 다는 낫다'(Zalusky 1998), 차선의 방법(Lindon 2000), 치료 적 타협안(Benson 등 2001)이라는 시각으로서 수용하는 입 장이다. Scharff(2013)는 치료가 전부 원격 세션만으로 이루 어져서는 정신분석적 정신치료가 불가능하다고 한 Sachs의 주장을 인용하였다. 그가 반드시 환자와 치료자가 정기적으 로 직접 만나는 세션을 가져야 한다고 하고, 정신분석적 치료 의 가치와 그 범위를 확장하기 위해서는 원격 정신분석적 치 료에 대한 선택에 신중을 기해야 할 것이라고 한 조언을 인용 하였다. 저자 역시 이와 같은 시각에 동의한다. 원격 정신분석 적 치료의 필요성을 거부할 수 없지만, 신중하게 수용해야만 한다. 불가피한 경우에만 치료적 타협안이 되어야 하고, 원격 정신분석적 치료를 주된 치료방법으로 선택하더라도 정기적 으로 계획된 직접 만나는 세션을 가질 것을 고려해야 한다. 이 렇게 함으로써 한 방에 함께 있는 것을 피하려 하고, 함께 있 기 위해 필요한 수고를 거부하는 환자와 치료자의 무의식적 저항이 드러날 기회를 얻게 된다. 이 무의식적 저항이 이해되 고 해석되지 않은 채 치료가 진행된다면, 가장 나쁘기로는 
원격 정신분석적 치료에서 판타지를 실현하는 가상현실을 제공하는 서비스 그 이상의 의미를 찾기 어려울 수도 있다.

\section{원격 정신분석적 치료에 대한 임상적 문제들}

이제 원격 정신분석적 치료를 임상에 적용할 때 어떠한 문제점들이 생기는지 살펴볼 것이다. 먼저 기존의 정신분석 적 치료와 원격 정신분석적 치료를 비교한 문헌들을 살펴보 고 그 차이점과 유사점을 이해하고, 원격 정신분석적 치료의 임상적 문제와 그 해결책을 문헌 고찰을 통해서 살펴본 후에, 저자의 견해도 밝힐 것이다. 마지막으로 원격 정신분석적 치 료를 고려하는 치료자들에게 판단과 선택의 지침이 될 수 있 는 원격 정신분석적 치료의 적응증과 비적응증을 살펴보려 고 한다.

원격 정신분석적 치료 세션에서도 치료자의 공감적 수용 과 해석 능력은 유지되고, 환자의 자유연상과 전이감정의 발 달도 차이가 없다는 의견이 많은 연구자들에 의해 제시되었 다(Hanly 2007; Aryan 등 2009; Lutenberg 2011). Scharff (2013)는 같은 환자의 기존 정신치료 세션과 원격 정신분석 적 치료 세션을 블라인드 테스트했을 때 차이가 없었다고 보고했다. Scharff(2012a)는 전화 세션이나 스카이프의 영상 을 끈 상태의 세션은 환자가 카우치에 누웠을 때 치료자가 환 자의 시야 밖에 있는 것과 같은 효과를 낼 것으로 보았다. 환 자의 자유연상을 촉진하고 치료자의 자유롭고 편안한 집중 (free floating attention)을 가능하게 한다고 생각했다. 그리하 여 원격 세션이 시작되면서 이전까지 드러나지 않았던 전이 와 병리가 드러나는 경우도 종종 있다고 보고했다.

반면 원격 세션이 직접 만나는 세션과 같을 수가 없다는 시각 또한 충분한 논리를 가지고 있다(Russell 2015; Turkle 2017). 다르다는 시각은 바로 원격 세션의 문제를 우려하는 시각으로 이어진다. 시야의 제약과 비언어적 신호(후각, 몸 동작)를 인식할 수 없다는 것은 원격 세션의 단점으로 흔히 지적되고 있다. Brahnam(2017)은 통신기술의 기술적 제약 에 따르는 문제가 정신분석적 치료에 어떤 영향을 주는지를 연구한 여러 자료들을 리뷰하여 아래와 같이 요약하였다. 전 화나 스카이프의 소리, 영상 신호가 실제 환자와 치료자의 것과 똑같지 않다. 인터넷 속도가 소리와 영상을 실시간으로 전달하지 못해 발생하는 단점도 무시할 수가 없다. 환자와 치료자의 말이 끊기고, 영상과 소리가 일치하지 않고 지연되 며, 가장 큰 문제는 한참 동안 접속이 불가능할 수도 있다. 또 잡음과 흐린 영상, 목소리의 왜곡도 일어난다. 이런 문제는 가끔 일어날 수 있는 것이 아니라, 거의 매 세션마다 일어날
수 있는 흔한 문제이다. Russell(2015)은 원격 세션에서는 통 신의 접속이 유지되고 있는지 확인하기 위해 환자와 치료자 가 더 많이 이야기하게 되고, 침묵을 기다리는 것이 더 힘든 점을 지적하였다.

Scharff(2012a)는 원격 정신분석적 치료에서 통신기기의 기술적 문제는 환자에게는 치료자의 공감의 실패와 똑같이 인식된다고 하면서, 기술적 문제가 치료자의 공감 실패로 인 식된 사례를 제시하였다. 통신장애로 잠깐 동안 치료자가 환 자의 이야기를 듣지 못했는데, 치료자는 환자가 침묵하는 것 으로 인식하고 그것을 저항으로 해석했던 것이다. 환자는 치 료자의 해석에 당황했다. 나중에 환자가 하는 이야기가 통신 장애로 인해 치료자에게 들리지 않았던 것임을 알게 되었지 만, 환자는 어린 시절 어머니와 떨어져 있을 때, 어머니에게 자신의 이야기를 전할 수가 없어서 거절당하고 방치되는 기 분을 느꼈던 기억을 떠올린다(Scharff 2012a). 이와 같이 단 영점 몇 초의 차이로 환자와 치료자의 목소리와 영상이 지 연되어 전달되어도, 환자가 이야기하는 동안 치료자가 반응 하지 않거나 뒷북을 치는 것으로 인식될 수 있다. 또 환자와 치료자의 눈맞춤이 자연스럽지 않게 느껴지고, 서로의 목소 리와 영상이 왜곡되어 전달될 경우에도 서로의 감정이 제대 로 전달될 수 없을 것이다.

우리가 신중하게 고려해야 하는 것 중에 원격치료에서는 세팅을 조정하는 역할이 치료자에서 환자로 이전되거나, 최 소한 환자가 치료자와 동등한 정도로 치료 세팅 조정의 역 할을 하게 된다는 사실이다(Brahnam 2017; Dettbarn 2013). 치료자의 방에서 두 사람이 만나는 기존의 정신분석적 치료 에서는 치료자가 그 방의 모든 것을 조정했다. 온도, 밝기, 인테리어, 가구 배치를 결정하고, 세션 중에 치료실 안으로 들어오는 소리, 사람, 방해하는 상황 등에 대해서 치료자가 조절하고 관리한다. 그러나 원격치료에서는 환자가 어디에 서 어떻게 치료공간에 접속할지를 결정한다. 환자는 자기 방 에서, 자신의 사무실에서 혹은 자동차 안에서 접속할지 결정 한다. 혼자만 있는 공간을 선택할지 사람들이 다니는 외부공 간을 선택할지, 카메라의 해상도와 위치를 조정함으로써 보 이는 범위를 결정하고, 그 공간의 온도, 밝기, 배경소리도 선 택할 수 있다.

환자가 의식적이든 무의식적이든 선택하는 치료공간의 세 팅은 모두 역동적 의미가 있다. 저자가 치료했던 환자의 증 례를 예로 들면, 자신의 방에서 스카이프로 치료를 이어오던 환자가 겨울 동안 방에 난방을 하지 않았다. 그러고는 세션 을 시작할 때마다 '이 방이 너무 추워요'라고 말하곤 했다. 환자는 따뜻하고 밝아 보이는 치료자의 방을 상상하면서 '내 가 있는 곳과 선생님이 있는 곳은 너무나 차이가 난다'고 불 
평했다. 이 환자는 먼 거리 때문에 불가피하게 스카이프로 치료를 이어가고 있었는데, 치료자와 만나지 못하고 떨어져 치료를 할 수밖에 없는 상황을 치료자가 추위에 떨고 있는 자신을 냉정하게 내버려두는 것으로 느꼈다. 어린 시절 자신 에게 무척 실망한 아버지가 추운 겨울 대문 밖으로 자신을 내쫓았던 것과 같이 말이다. 환자는 자신의 방을 춥게 내버 려둠으로써 치료자가 자신을 추운 밖에 내버려두고 있다고 느끼는 내적 판타지를 외현화(externalization)한 것이었다.

이 증례의 경우는 환자가 공간의 세팅을 결정한 것에 대 해, 그 역동적 의미를 이해함으로써 치료과정을 촉진시킬 수 있었다. 그러나 환자에게 큰 저항이 생길 경우 환자는 세팅 을 조정하여 치료자가 자신의 저항에 개입할 수 있는 기회를 없앨 수 있다. 예로 큰 저항이 일어난 환자는 치료 세션 도중 에 통신기기를 켜 둔 채, 아무런 언급 없이 조용히 그 자리를 떠나버릴 수 있다. 직접 만나는 치료 세션에서는 환자가 치료 자 몰래 그 자리를 떠날 수가 없지만, 전화나 영상을 끈 스카 이프 세션의 경우에는 환자가 그 자리를 떠나더라도 치료자 는 전혀 모를 수 있다. 한참을 환자의 침묵을 기다리다가 조 심스럽게 환자에게 무슨 생각을 하고 있는지 물어보게 될 것 이다. 세션이 끝날 시간이 되어서야 환자가 그 자리를 떠났 다는 것을 깨닫게 될 수도 있다.

치료 세팅을 환자가 조정하게 됨으로써 일어나는 심각한 문제는 강력한 저항이 있을 때 발생한다. 기존 정신분석적 치 료에서 견고한 세팅은 환자의 저항을 인식하고 작업할 수 있 도록 돕는 데 반해, 원격치료 세팅에서는 환자가 자신이 조정 할 수 있는 세팅을 강력한 방어에 이용하게 될 것이다. 세팅 을 스스로 조정할 수 있다는 것이 환자로 하여금 전능감의 욕 구를 충족시키고 심하게 퇴행하게 만들 수 있다. Chodorow 는 전화 분석의 경험을 "환자가 급속도로 퇴행하는 것이 눈 에 보였다. 가끔은 무섭기까지 했다. $\cdots$ 치료실 안에서 만난 다면 더 편하게 그 환자를 볼 수 있을 것 같다"라고 이야기하 였다(Chodorow 2004, as cited in Scharff 2012a). 원격 정신 분석적 치료에서 환자에게 심한 퇴행과 저항이 발생한 경우 치료자가 환자의 저항에 개입할 수 있는 여지가 상당히 줄어 들며 환자가 치료과정에서 드러내는 파괴적 공격성을 포용 할 수 있는 힘(containing)도 줄어들게 된다. 이때 치료자의 역전이 또한 강력하게 발생할 수 있어, 환자의 원초적 부정 적 전이와 치료자의 역전이가 맞물려 치료는 교착 상태에 빠 지게 될 수 있다.

Scharff(2012a)는 원격 세션에서 환자와 치료자가 서로 보 이지 않는 것이 자유연상과 치료자의 자유로운 집중을 촉진 시킬 것이라고 생각했지만, 환자와 치료자의 치료과정에 대 한 저항이 거세질 경우 서로 보이지 않는 것은 그 저항이 숨
을 수 있는 강력한 방어벽이 될 수 있다고 우려한 연구자들도 있으며(Scharff 2012a; Fishkin 등 2011) 저자 역시 그 의견 에 동의한다. 목소리를 낮추고 속삭이듯이 이야기하거나, 스 피커 볼륨을 낮추고 치료자의 목소리를 듣지 않거나, 다른 전 화를 받거나, 사적인 통화같이 이야기하는 등의 환자의 저항 에 치료자는 직면하게 된다(Scharff 2012a). 환자만이 아니라 역전이적 저항이 생긴 치료자는 수화기 너머 들리는 소리에 집 중하지 않고 심지어는 다른 일을 하게 될 수도 있다(Fishkin 등 2011). 물론 카우치 뒤에 앉아서도 스마트폰을 들여다보 거나 졸음을 못 견디고 잠을 잘 수도 있다. 그러나 원격 세션 에서는 환자와 그 방에 함께 있지 않다는 사실로 인해, 치료 자 자신의 역전이를 깨닫는 데 무디어지고 그 유혹에 훨씬 쉽게 굴복할 가능성이 있다.

이런 문제의 해결책으로는 원격치료 전에 반드시 직접 만 나는 치료기간을 가지고 환자의 정신역동과 정신심리적 병 리의 정도를 제대로 평가하여야 한다. 그리고 원격 세션을 시 험적으로 가지는 기간을 통해서 환자가 치료 세팅을 스스로 조정하는 데 책임질 수 있는 적절한 자아 기능을 가졌는지 평가가 필요하다. 상당 기간의 직접 만나는 정신분석적 치료 를 해오던 환자가 불가피하게 원격치료로 전환할 경우에도 원격 세션을 시험적으로 가지는 기간을 두는 것을 고려해보 는 것을 권한다. 그리고 원격치료로 전환해도 주기적으로 직 접 만나는 세션을 계획하여, 직접 만나는 치료 세션을 유지 하는 것이 필요하다(Sachs 2003, as cited in Scharff 2013).

원격치료에서는 환자가 치료자의 목소리나 화면으로 보 이는 치료자의 부분 영상(대체로 얼굴과 상체의 약간만 영 상에 잡힐 것이다)을 부분 대상(part object)으로 인식하게 되어서 비현실적인 이상화 전이가 일어나기가 쉽고, 자신의 전이감정을 보다 미성숙한 방어기제를 통해 투사하게 될 가 능성이 높아진다(Scharff 2012a). 그리고 치료자는 그 전이 물을 수용하기가 힘들어진다. 멀리 떨어져 있어도 치료가 지 속될 수 있다는 것은 환자가 치료자와의 분리(separation)와 상실(loss)을 부정하고 거부하는 데 편승하게 되기가 쉽다. 반대로 치료는 지속되지만 몸이 함께 있지 못하니, 몸으로써 존재를 느끼는 것은 상실하게 되는 모순이 일어난다. 치료공 간의 탈공간화, 환자와 치료자의 탈신체화(disembodiment) 는 갈등을 회피하려고 하는 인간의 원초적인 판타지에 편승 하여 환자와 치료자 모두 쉽게 퇴행하게 하고 치료과정에서 발생하는 저항을 인식하기가 어려울 수 있다.

이에 연관해서 Mirkin(2011)은 응급 상황으로 인해 계획 에 없었던 원격 세션을 가지게 되는 경우에 발생하는 문제 를 제시했다. 환자가 자신이 원할 때 치료자와 만날 수 있다 는 지대한 만족감(gratification)을 얻게 되고, 이 자체로 행 
동화(enactment)의 기회가 될 수 있다고 했다. 이 경우 원격 세션에 대한 환자의 판타지를 탐색함으로써, 원격 세션을 욕 구를 충족시키는 수단이 아니라 유용한 치료적 도구로써 사 용할 수 있을 것이라고 했다.

마지막으로 전화나 인터넷을 이용하여 원격치료를 하는 경우, 해킹이나 도청 등으로 비밀 유지를 신뢰할 수 있는지 에 대한 의문이 많이 제기되었다. 수십 년간 축적된 임상자 료에서 인터넷 서비스를 이용한 음성 및 화상통신(Skype)의 안전성을 신뢰할 수 있다는 의견도 있으나(Scharff 2012a), 국내 상황에 대한 체계적인 연구는 아직 없으며, 여전히 환자 의 비밀 유지를 위해 보다 안전하고 신뢰할 수 있는 원칙과 기술 도입을 위해 연구하는 것이 필요하다.

\section{원격 정신분석적 치료의 적응증과 비적응증}

원격 정신분석적 치료가 가능한지, 불가능한지를 판단하기 이전에 환자나 치료자가 원격 정신분석적 치료를 요구하는 이면의 역동적 의미를 이해하는 것이 우선적으로 이루어져야 한다(Scharff 2012a). 환자의 신경증적 필요(neurotic need), 전이의 행동화(enactment)일 수도 있고, 반면 현실 적응적 선택, 혹은 방어적 선택이 혼재한 현실적 이유로 원격 정신분 석적 치료를 필요로 할 수도 있다. 원격 정신분석적 치료를 결정할 때, 역동의 이해와 현실 적응적 요구를 중립적으로 조 율해야 한다.

이제 원격 정신분석적 치료를 피해야 할 경우와 가능한 경 우를 살펴볼 것이다. 이것은 치료 방식을 선택하기 위해 판단 이 필요할 경우 지침이 될 수 있을 것이다. 우선 청력, 발성, 음성에 장애가 있는 환자와 치료자는 원격치료를 할 수가 없 다. 자살의 위험이 있는 경계선 수준의 환자, 약물남용의 문 제가 상존하는 경우, 약물치료가 필요한 경우는 환자의 안전 을 위해서 치료자와 직접 만나서 치료를 해야 한다. 즉, 직접 만날 수 있는 치료자를 찾도록 권하는 것이 필요하다. 치료 관계를 유지하고 세팅에 대한 책임을 나누어질 수 없는 환 자는 원격치료 중에 강한 저항이 발생할 경우 치료과정의 교착을 풀기가 매우 힘들기 때문에 원격 정신분석적 치료는 피하는 것이 좋겠다. 직접 만나는 관계에 의존적인 환자가 불 가피하게 치료가 중단될 경우, 원격치료보다는 직접 만날 수 있는 치료자에게 연계하는 것이 바람직하다(Scharff 2012a, 2013; Leffert 2003). Zalusky(1998)는 친밀함(intimacy)에 대 한 심각한 문제가 있는 환자는 원격 정신분석적 치료에서 위 장된 친밀함(pseudointimacy)이 형성될 가능성이 높아서 환 자의 병적인 방어를 부추기게 된다고 했다.

원격 정신분석적 치료가 가능한 경우를 살펴보면 직장, 거
주지의 이동, 환자의 병으로 인해 치료를 지속하기 어려운 경우에 기존의 직접 만나는 치료를 원격치료로 전환할 수 있 다. 또 다른 나라에 거주하는 경우 다른 선택이 불가능하다 면 원격치료를 고려할 수 있겠다. 이 경우에 직접 만나서 치 료 형태를 상의하고 시험적인 원격치료 세션을 통해서 가능 성을 평가하고 적절한 시간 간격으로 직접 만나는 치료를 유 지하는 것이 좋다(Scharff 2012a, 2013; Zalusky 1998). Zalusky(1998)는 원격 정신분석적 치료 이전의 치료에서 치료 동맹이 충분히 형성된 경우에 원격 정신분석적 치료로 전환 할 것을 제안하였다. 또 Scharff(2012a)와 Zalusky(1998)는 외상과 관계된 해리 증상이 주된 호소인 환자나 심한 외상과 연관하여 친밀함에 대한 두려움이 있는 경우, 치료자와의 직 접 만나는 두려움이 원격치료를 적용하면 보다 극복하기 쉬 울 수도 있다는 의견을 냈다.

\section{결 론}

원격 정신분석적 치료는 현대사회의 초연결성과 탈공간화 라는 변화로 인해 피할 수 없는 사회적 요구이며 우리의 도 전이 되었다. 정신분석은 현대인들이 등한시하는 모호함, 불 편함, 기다림의 가치를 수호하고 있다. 이 가치들은 사람들 이 서로를 내재화하고 공감하고 내적 친밀함을 형성하는 데 반드시 필요한 것들이다. 이에 반해 원격치료는 정신분석의 가치에 상반되는 면들을 가지고 있는 것이 사실이다. 이 때문 에 많은 치료자들이 원격 정신분석적 치료의 장단점을 가지 고 논의를 이어오고 있다. 원격 정신분석적 치료의 유용성에 대해 편견 없이 인정하고, 임상적 문제들을 제대로 인식하고 이해하는 것은 앞으로 불가피하게 도래할 원격치료 시대를 대비하고 정신분석의 가능성과 가치를 확대하기 위해 반드 시 필요하다.

\section{Conflicts of Interest}

The author has no potential conflicts of interest to disclose.

\section{ORCID iD}

Chang-Hun Lee: https://orcid.org/0000-0002-3091-7966

\section{REFERENCES}

Akhtar S. Editor's introduction: internet. Int J Appl Psychoanal Stud 2010; 7:88-89.

Aryan A, Berenstein S, Carlino R, Grinfeld P, Lutenberg J, editors. Psicoanálisis por teléfono, Panel on telephone analysis. Chicago, IL: International Psychoanalytical Association Congress;2009.

Benson RM, Rowntree EB, Singer MH. Final report of ad hoc committee on training analysis via telephone. Unpublished report to the Board on Professional Standards of the American Psychoanalytic Association;2001.

Boase J, Horrigan JB, Wellman B, Rainie L. The strength of internet 
ties. Washinton, DC: Pew Internet and American Life Project;2006.

Brahnam S. Comparison of in-person and screen-based analysis using communication models: a first step toward the psychoanalysis of telecommunications and its noise. Psychoanalytic Perspectives 2017;14: $138-158$.

Carr N. The shallows: what the internet is doing to our brains. New York, NY: W. W. Norton;2010.

Dettbarn I. Skype as the uncanny third. In: Scharff JS. Psychoanalysis online: mental health, teletherapy, and training. London: Karnac Books; 2013. p.15-25.

Fishkin R, Fishkin L, Leli U, Katz B, Snyder E. Psychodynamic treatment, training, and supervision using internet-based technologies. J Am Acad Psychoanal Dyn Psychiatry 2011;39:155-168.

Hanly C. Case materical from a telephone analysis. Panel presentation. Seattle, WA: American Psychoanalytic Association Congress;2007.

Konrath SH, O'Brien EH, Hsing C. Changes in dispositional empathy in American college students over time: a meta-analysis. Pers Soc Psychol Rev 2011;15:180-198.

Leffert M. Analysis and psychotherapy by telephone: twenty years of clinical experience. J Am Psychoanal Assoc 2003;51:101-130.

Lindon J. Psychoanalysis by telephone. In: Aronson JK. Use of the telephone in psychotherapy. Northvale, NJ: Jason Aronson;2000. p.3-13.

Lutenbeg J. Presentaciónn de material clínico del análisis telefónico. In: Lutenberg J. Tratamiento psicoanalitico telefónico. Lima: Siklos SRL; 2011. p.113-142.

Mirkin M. Telephone analysis: compromised treatment or an interesting opportunity? Psychoanal Q 2011;80:643-670.
Nie NH, Erbring L. Internet and society: a preliminary report. IT \& Society 2002;1:275-283.

pmg [Internet]. pmg 지식엔진연구소. [cited 2016 Apr. 05]. Available from: https://terms.naver.com/entry.nhn?docId=3377297\&cid=4366 $7 \&$ categoryId $=43667$.

Richards AK. Talking cure in the 21st century: telephone psychoanalysis. Psychoanal Psychol 2001;18:388-391.

Russell GI. Screen relations: the limits of computer-mediated psychoanalysis and psychotherapy. London: Karnac Books;2015.

Saul LJ. A note on the telephone as a technical aid. Psychoanal Q 1951;20: 287-290.

Scharff JS. Clinical issues in analyses over the telephone and the internet. Int J Psychoanal 2012a;93:81-95.

Scharff JS. Letter to the editor. On: reply to 'Skype and privacy.' Int J Psychoanal 2012b;93:1039-1041.

Scharff JS. Technology-assisted psychoanalysis. J Am Psychoanal Assoc 2013;61:491-510.

Stadter M. The influence of social media and communications technology on self and relationships. In: Scharff JS. Psychoanalysis online: mental health, teletherapy, and training. London: Karnac Books;2013. p.3-14.

Turkle S. Empathy machines: forgetting the body. In: Tsolas V, AnzieuPremmereur C. A psychoanalytic exploration of the body in today's world: on the body. New York, NY: Routledge;2017. p.17-27.

Zalusky S. Telephone analysis: out of sight, but not out of mind. J Am Psychoanal Assoc 1998;46:1221-1242. 